\title{
OP-17 EFFECTIVENESS OF 'UNIVERSAL' HEALTH INSURANCE FOR WOMEN IN URBAN SLUMS OF RAIPUR, CHHATTISGARH
}

Sulakshana Nandi, ${ }^{1}$ Rajib Dasgupta, ${ }^{2}$ Samir Garg, ${ }^{3}$ Dipa Sinha, ${ }_{1}^{4}$ Sangeeta Sahu, ${ }^{5}$ Reeti Mahobe ${ }^{5}$. ${ }^{1}$ PHRN - Public Health Resource Network, Raipur (Chhattisgarh), India; ${ }^{2}$ Centre of Social Medicine and Community Health, Jawaharlal Nehru University, New Delhi (Delhi NCR), India; ${ }^{3}$ SHRC - State Health Resource Centre, Raipur (Chhattisgarh), India; ${ }^{4}$ PHRN - Public Health Resource Network, New Delhi (Delhi NCR), India; ${ }^{5}$ Chaupal - Gramin Vikas Prashikshan Evum Shodh Sansthan (Chaupal), Raipur (Chhattisgarh), India

\subsection{6/bmjgh-2016-EPHPabstracts.17}

Background Promoted as a vehicle for achieving universal health coverage (UHC), the Rashtriya Swasthya Bima Yojana (RSBY) was expanded in Chhattisgarh to a universal scheme Mukbyamantri Swasthya Bima Yojana (MSBY) plus RSBY - in 2012 by the state government. The present study, conducted in urban slums of Raipur, capital of Chhattisgarh, aimed to assess issues of coverage and utilisation under RSBY/MSBY and whether it can effectively address health concerns of the urban poor, with a focus on women's medical conditions and their experiences. It tried to assess the extent to which cashless treatment is available under RSBY/MSBY. Simultaneously it seeks a layered understanding of claims of universal coverage through the insurance route. 
Methods The study was quantitative in nature. Primary data were collected from a sample of individuals who were hospitalised in the last six months prior to the study, identified through Mitanins (women community health workers). The surveyors interviewed all identified patients and, additionally, used snowball technique to expand sample size. The total number of patients interviewed was 367 (284 women and 83 men). Here, we document the experience of women patients: 282 women, of $65 \%$ belonged to Other Backward Castes (OBC), $17 \%$ to Scheduled Castes (SC), 4\% to Schedule Tribes (ST) and 13\% to General (non OBC, non SC, non ST). A structured interview guide was applied.

Findings A slightly higher percentage of women $(68 \%)$ than men $(65 \%)$ were enrolled in RSBY/MSBY. Only 5\% of the enrolled received the list of empanelled hospitals; $57 \%$ received a smart card on enrolment day as per the norm.

Around $78 \%$ of hospitalised women presented gynaecological or obstetric conditions (including 200 childbirths), while men were mainly hospitalized for respiratory and water- or foodborne diseases. Hospitalisation of women took place in public facilities $(57 \%)$, in private facilities $(37 \%)$, or in both $(5 \%)$. Higher proportions of women whose families were not enrolled went to the public sector, for all conditions. Women accessed the public sector more for pregnancy $(63 \%)$ and other gynaecological conditions $(76 \%)$, and the private sector $(55 \%)$ for nongynaecological conditions.

Half of the hospitalised women were not enrolled in RSBY/ MSBY. Of the enrolled, 36\% were able to use insurance, with usage higher in empanelled private facilities (71\%) than in public facilities (25\%). Insurance was used in $17 \%$ of delivery cases $(28 \%$ in private and $10 \%$ in public). Utilisation of insurance was higher for $\mathrm{C}$-section than for vaginal deliveries.

Only 4\% of women did not incur out-of-pocket expenses (OOP), with average OOP for non-gynaecological cases much higher than for gynaecological cases. Overall, OOP were made on fees charged (52\%), medicines (18\%) and diagnostics $(15 \%)$. Of the women who incurred OOP, $90 \%$ had to spend on transportation, and $76 \%$ on medicines. Average OOP in private facilities was more than six times higher than in public facilities. Women incurred OOP despite using RSBY/MSBY, with average OOP much higher for women who used RSBY/MSBY in private facilities (INR 10,733) than in public facilities (INR 2,518). The average amount booked under RSBY/MSBY for vaginal birth in private hospitals (INR 7,607) was twice that of the amount booked in public hospitals (INR 3,775). Women borrowed $(37 \%)$, used savings (61\%), and seven women sold/mortgaged valuables to pay for treatment.

Discussion While our study finds that there has been an increase in enrolment since the introduction of the RSBY/MSBY, $43 \%$ of the urban slum population in Raipur remains uncovered. Moreover, the overall usage of insurance for hospitalisations is very low. This is despite the fact that Raipur district has the highest number of empanelled facilities, most of them in Raipur city and making the highest amount of claims in the state.

In the utilisation of insurance, there seems to be a bias towards surgical procedures, mainly in the private sector. Utilisation was higher for non-gynaecological conditions (49\%) and the usage of RSBY/MSBY cards for C-sections was more than twice than that for vaginal deliveries. With respect to cost of health care, the private sector is more expensive than the public sector in every situation, even when using insurance.
Our study shows that 'universal' health insurance does not automatically translate to universal health coverage. Despite having a 'universal' health insurance scheme Chhattisgarh is not able to provide financial protection and decent access to the urban poor women for hospitalisations. In evaluating the impact of health insurance schemes, it is imperative that the efficacy of health insurance be assessed in terms of providing financial protection, and equitable and effective healthcare access for vulnerable and marginalised populations like the urban poor.

Grant funding (Paul Hamlyn Foundation, London) for research but no other competing interests. 